ECCOMAS

\section{Proceedia}

COMPDYN 2021

$8^{\text {th }}$ ECCOMAS Thematic Conference on Computational Methods in Structural Dynamics and Earthquake Engineering M. Papadrakakis, M. Fragiadakis (eds.) Streamed from Athens, Greece, 28 - 30 June 2021

\title{
REAL-TIME HYBRID SIMULATION OF A STRUCTURE WITH CIRCULAR FIBER REINFORCED ISOLATORS
}

\author{
Carlos Riascos $^{1}$, Semion Klopov ${ }^{2}$, Johannio Marulanda ${ }^{2}$, Peter Thomson ${ }^{2}$ \& Giorgio Serino ${ }^{3}$ \\ ${ }^{1}$ Program of Civil Engineering, Universidad del Quindío, Armenia, Colombia \\ cariascos@uniquindio.edu.co \\ ${ }^{2}$ School of Civil Engineering and Geomatics, Universidad del Valle, Cali, Colombia \\ \{semen.klopov, johannio.marulanda, peter.thomson\}@correounivalle.edu.co \\ ${ }^{3}$ Università degli Studi di Napoli Federico II, Naples, Italy \\ giorgio.serino@unina.it
}

\begin{abstract}
More than $87 \%$ of the Colombian population lives in zones of intermediate and high seismic hazard, which has generated an increasing interest toward base isolated structures. Nowadays, this technique has been mainly applied to hospitals and bridges. However, it is necessary to expand the action field of isolators to diverse kind of structures in countries with high seismic hazard. In this direction, the performance of circular unbounded fiber reinforced elastomeric isolators (U-FREI) was studied in a two degrees-of-freedom (DoF), medium scale structure, under seismic excitation. This evaluation was achieved employing a Real-Time Hybrid Simulation (RTHS), which is defined as a modern cyber-physical technique used for the experimental evaluation of complex systems, that treats the system components with predictable behavior as a numerical substructure, and the components that are difficult to model as an experimental substructure. In this case, the main structure was considered as the numerical substructure and a couple of U-FREI was treated as the experimental substructure. The RTHS was evaluated using a set of Current Assessment Measurements, where an accurate tracking of the transfer system was determined. Furthermore, the experimental results were compared with Shaking Table Tests (STT) developed at University of Naples Federico II. Particularly, peak and RMS comparison of force and acceleration signals showed a similar behavior of the RTHS according to the STT results. Overall, both approaches demonstrated that the U-FREI were able to reduce more than the $70 \%$ of the structural drift with respect to the fixed structure, and the applied RTHS methodology was verified.
\end{abstract}

Keywords: structural control, real-time hybrid simulation, unbounded circular fiber reinforced elastomeric isolator, current assessment measurements. 


\section{INTRODUCTION}

Earthquakes are one of the main natural hazards in countries of the Pacific zone such as Colombia, Mexico, Ecuador, Chile and Japan. To counteract the effect of the earthquake, there are two widely accepted and implemented alternatives. The first consists in isolating the structure at the base, thus reducing the energy input of the earthquake to the building [1-3]. While the second one concentrates in mitigating, through auxiliary devices, the energy that has been transmitted by the earthquake to the structure [4-6]. In a conventional design, the building will dissipate this energy through vibrations that can lead to the generation of damage in its structural and non-structural elements.

In response to this issue, one of the alternatives for structural control that became popular in Japan was the seismic isolation, due to its great performance during the Kobe earthquake of 1995 [7]. De la Llera et al. in [8] has shown the positive experience of the base isolation application with budget limitation and other technological constraints. A cost reduction alternative consists of simplifying the isolator installation process, due to it can be located between the foundation and the structure without bonding at the contact surfaces. This simplified installation method is named 'unbonded application' which has been recently investigated on Fiber Reinforced Elastomeric Isolators (FREI) [9].

Unfortunately, to validate the performance of such systems in civil structures would be necessary to implement full-scale experimental tests. These tests require enormous resources that can be prohibitive for some projects. In contrast, the evaluation of non-conventional and earthquake-prone structures is currently being promoted using Real-Time Hybrid Simulation (RTHS). These simulations allow the study of complex systems by classifying components that are easy to model as numerical substructure and components whose behavior is difficult to predict as experimental substructure [10-12]. Thus, the numerical substructure is represented computationally, while the experimental substructure is constructed and tested physically [1315]. Therefore, RTHS technique involves advantages as low cost, small space, low loading capacity requirements $[12,16]$.

This study addressed this issue developing a RTHS for a structure with unbounded seismic isolators U-FREI (Unbounded Fiber Reinforced Elastomeric Isolators).

\section{SHAKING TABLE TEST (STT)}

\subsection{Main structure}

Losanno et al. [17] conducted a series of Shaking Table Tests (STT) with an experimental two degrees-of-freedom (DoF) base isolated system. This structure was installed at the Department of Structures for Engineering and Architecture (DiST) of the University of Naples Federico II in Italy. A cylindrical U-FREI was used bellow each column. Also, previously in the research [18] both polyester and carbon reinforcement were considered, where their characterization was developed through uniaxial shear and compression tests. In this case, the results obtained by Losanno et al. in [17] are used as the reference data, with the aim of validating the RTHS results achieved in this application. The reference structure consists of a steel frame, with a total height of $2.9 \mathrm{~m}$ and plan dimensions of $2.65 \times 2.15 \mathrm{~m}^{2}$, as shown in Figure 1. The total weight of the structure is $77 \mathrm{kN}$, with a base load of $36 \mathrm{kN}$ and a top load of $41 \mathrm{kN}$. Additionally, the structural response was measured through 3-axis accelerometers (PCB356A17) and displacement sensors (Micro-epsilon ILD1402-600, Wenglor CP35MHT80) in each level. 


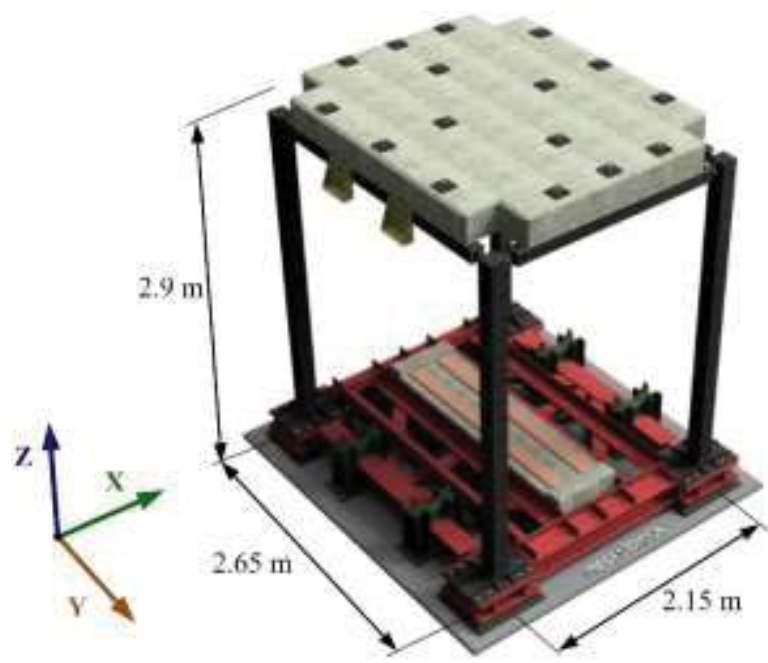

Figure 1: Scheme of the reference structure.

The dynamic characteristics of the main structure in fixed-based configuration were identified through shaking table tests in [19], and masses, natural frequency and damping ratio are presented in Table 1.

\begin{tabular}{cccc}
\hline$m_{\text {bottom }}(\mathrm{kg})$ & $m_{\text {top }}(\mathrm{kg})$ & $f_{n}(\mathrm{~Hz})$ & $\zeta(\%)$ \\
\hline 3675 & 4180 & 3.81 & 1.00 \\
\hline \multicolumn{4}{c}{ Table 1: Dynamic properties of the main structure. }
\end{tabular}

\subsection{Circular unbounded fiber reinforced elastomeric isolators}

The main structure was supported by four cylindrical U-FREI, as shown in Figure 2. These isolators have a diameter of $80 \mathrm{~mm}$ and total height of $44 \mathrm{~mm}$. Particularly, these U-FREIs are composed of 15 rubber layers with a thick of $2 \mathrm{~mm}$, which were reinforced by 14 polyester fiber layers with a thick of $1 \mathrm{~mm}$. The total height of rubber is $\mathrm{H}_{r}=30 \mathrm{~mm}$. The same manufacturing process is also described in Madera Sierra et al. [20].
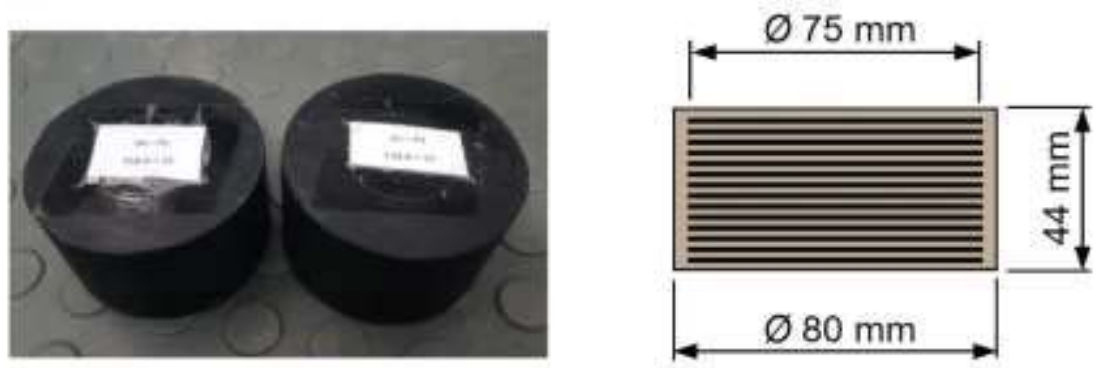

Figure 2: U-FREI.

The U-FREIs employed in the STT were characterized using a cyclic test with a maximum displacement of $9 \mathrm{~cm}$, i.e. $300 \%$ shear strain. The hysteretic behavior of two set of these isolators is shown in Figure 3, as references T1a and T1b. In this study, two set of isolators, with the same geometry of those used at University of Naples, were analyzed in the LINSE Laboratory at Universidad del Valle, Cali, Colombia. These isolators were characterized with an equivalent cyclic test that presents a maximum displacement of $5 \mathrm{~cm}$, whose results are 
indicated in Figure 3 as LINSE (Sp1) and LINSE (Sp2). A challenging non-linear behavior is exhibited by U-FREIs as recently confirmed by several attempts to develop accurate hysteretic models [21-23].

The effective lateral stiffness $K_{h, i}$ of the devices was calculated based on the peak-to-peak lateral response for each deformation cycle, as shown in Eq. (1), where $F_{\max , i}$ and $F_{\min , i}$ are the maximum and minimum values of the force during the $i$-th cycle, and $D_{\max , i}$ and $D_{\min , i}$ are the corresponding for the displacement. The equivalent damping ratio $\beta_{i}$ was estimated as a function of the dissipated area, $E_{d, i}$, during each deformation cycle, as shown in Eq. (2). Both parameters are shown in Figure 4.
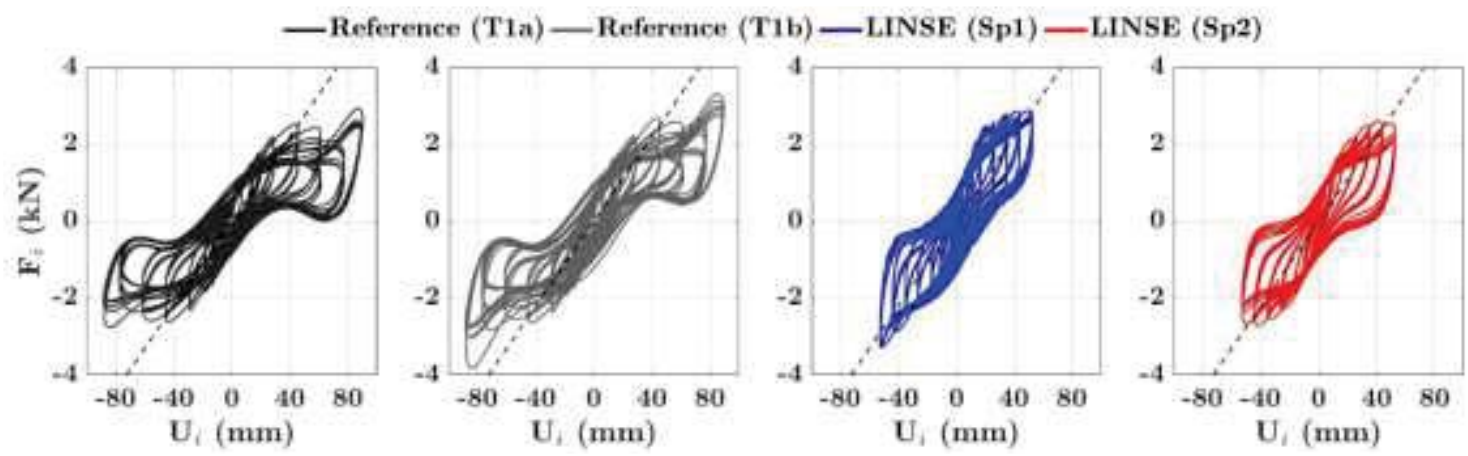

Figure 3: Hysteresis loops from cyclic tests for (a) Reference specimen T1a; (b) Reference specimen T1b;

(c) LINSE specimen 1; (d) LINSE specimen 2.

$$
\begin{gathered}
K_{h, i}=\frac{F_{\max , i}-F_{\min , i}}{D_{\max , i}-D_{\min , i}} \\
\beta_{i}=\frac{E_{d, i}}{2 \cdot \pi \cdot K_{h, i} \cdot\left(D_{\max , i}\right)^{2}}
\end{gathered}
$$
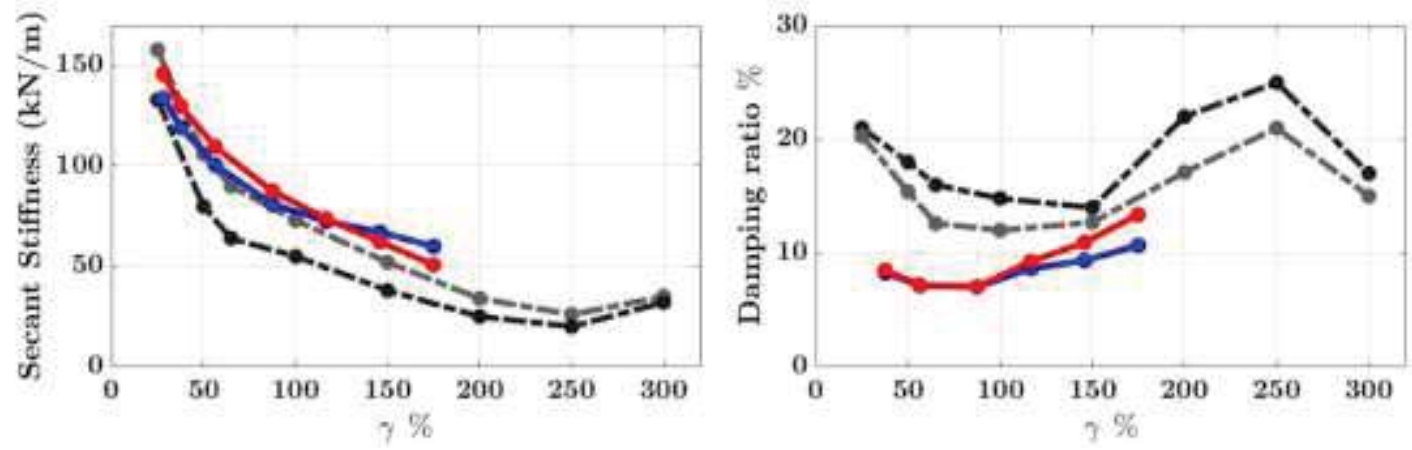

Figure 4: Comparison for the LINSE's and Federico II specimens of the (a) Secant stiffnesses and (b) Damping coefficients.

Even if secant stiffness of LINSE prototypes lightly exceeds the values from previous ones, it can be noted that a significantly lower damping is obtained especially at low deformation levels. This is probably due to a different rubber compound assumed in the manufacturing. 


\section{REAL-TIME HYBRID SIMULATION}

Real-time hybrid simulation (RTHS) is a modern cyber-physical technique used for the experimental evaluation of complex systems, which treats the components with predictable behavior of the system as numerical substructure and the components that are difficult to model as experimental substructure. In this implementation, the structural system (without isolators) is considered as the numerical substructure since it can be modeled with a high level of accuracy, whilst the isolators are considered as the experimental substructure.

One of the main challenges of the RTHS is the generation of the boundary conditions in the experimental substructure. This process demands a detailed knowledge of the actuators that apply the information obtained from the numerical integration. These actuators are known as transfer systems. In this implementation two decentralized transfer systems are included. One of them is focused on the normal force, which is directly applied to the isolator specimens, and the other reproduces the horizontal displacement at the base of the numerical substructure through a shear force.

The input of the RTHS is the base acceleration caused by the Campano-Lucano (CAM $50 \%$ ) earthquake scaled to the $50 \%, a_{g}(t)$, which corresponds to the first input of the numerical substructure model (see, Figure 6). The horizontal displacement of the numerical substructure at the isolator location was taken as the reference signal of the horizontal transfer system, $x_{i, d}(t)$. This process generates physically a displacement in the experimental substructure that corresponds to the measured displacement, $x_{i, m}(t)$, as shown in Figure 5. Furthermore, the vertical transfer system induces a normal force, $F_{v}(t)$, with a reference value of $19 \mathrm{kN}$, being this value, the structural weight supported by each isolator during the STT. In this direction, the shear force produced by the experimental substructure is the feedback force, $F_{i, f b}(t)$, and this signal is assigned as the second input of the numerical substructure.

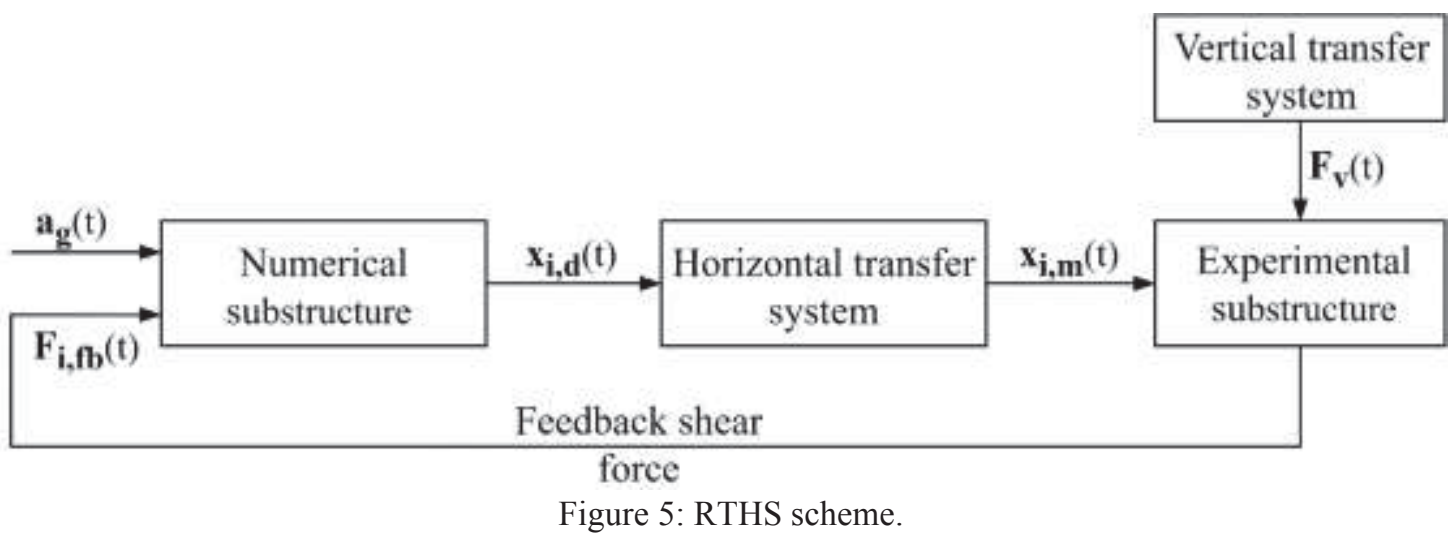




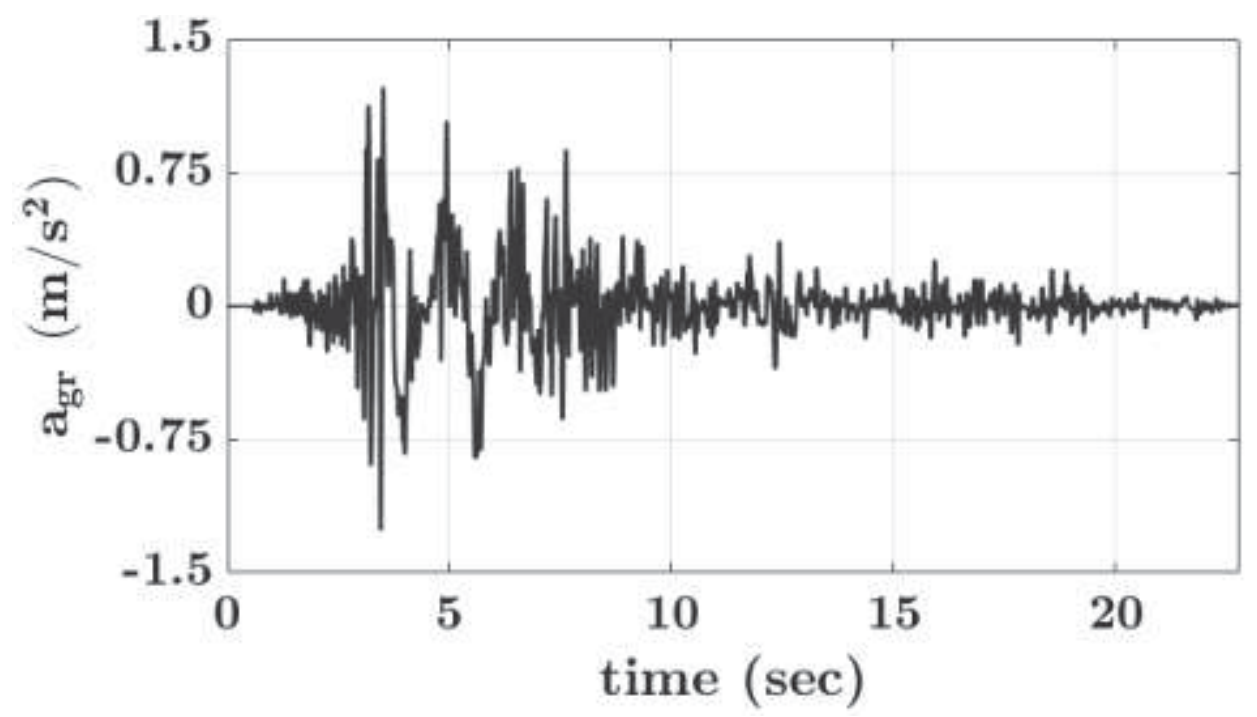

Figure 6: Ground acceleration of the CAM50\% earthquake.

\subsection{Numerical substructure}

The main structure was modeled as a two DoF system, as shown in Eq. (3). In this state space representation $m_{1}$ and $m_{2}$ are the bottom and top structural masses, as indicates in Figure 7. $k_{s}$ and $c_{s}$ are the stiffness and damping of the main structure, respectively. Moreover, $u_{i}(t)$ and $u_{s}(t)$ are the displacement of the isolators and the structural displacement. The four system states correspond to the isolator displacement, $x_{1}$, the structural displacement, $x_{2}$, the isolator velocity, $x_{3}$, and the structural velocity, $x_{4}$. As mentioned above, the system inputs are the ground acceleration, $a_{g}(t)$, and the isolator shear force, $F_{i, f b}$, which is measured during the RTHS. It is important to mention that the system output is the first state of the numerical model.
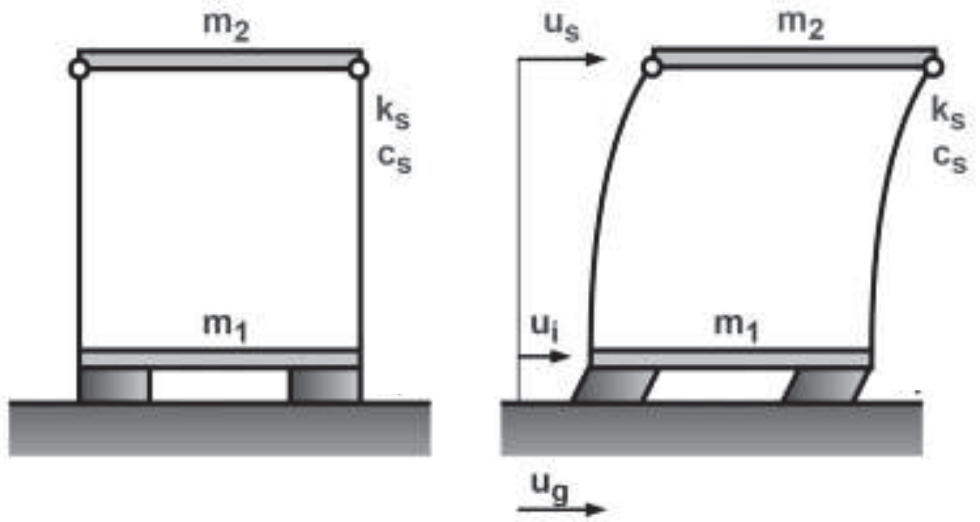

Figure 7: Main structure scheme.

$$
\left\{\begin{array}{l}
\dot{x}_{1} \\
\dot{x}_{2} \\
\dot{x}_{3} \\
\dot{x}_{4}
\end{array}\right\}=\left[\begin{array}{cccc}
0 & 0 & 1 & 0 \\
0 & 0 & 0 & 1 \\
-k_{s} / m_{1} & k_{s} / m_{1} & -c_{s} / m_{1} & c_{s} / m_{1} \\
k_{s} / m_{2} & -k_{s} / m_{2} & c_{s} / m_{2} & -c_{s} / m_{2}
\end{array}\right]\left\{\begin{array}{l}
x_{1} \\
x_{2} \\
x_{3} \\
x_{4}
\end{array}\right\}+\left[\begin{array}{cc}
0 & 0 \\
0 & 0 \\
-1 & -1 / m_{1} \\
-1 & 0
\end{array}\right]\left\{\begin{array}{c}
a_{g}(t) \\
F_{i, f b}(t)
\end{array}\right\}
$$




\subsection{Experimental substructure}

The behavior of the isolators in unbounded configuration is highly complex: because of the variation of the contact area $[14,18]$, it tends to decrease the horizontal stiffness and increase the energy dissipation. Also, U-FREI performs a phenomenon denominated roll-over as mentioned previously. A complete roll-over takes place when the original vertical face of the isolator is approaching the horizontal support $[9,18,24,25]$. It is shown that after the initial point of roll-over, a gradual softening of the isolators is produced, and after the end point of full roll-over, it can be observed an effect of stiffness hardening. Thus, in this study the U-FREIs are considered as the experimental substructure. For this purpose, an experimental setup was developed to couple the experimental substructure with the cybernetic component of the RTHS.

The experimental setup involves a moving plate, which is released in the vertical direction to allow the movement associated with the compression of the isolators. In addition, this plate is supported on linear bearings, which are oriented in the horizontal direction. In this configuration, two isolators are disposed in the experimental setup as shown in Figure 8. Thus, the opposition force of the isolators was measured by a load cell Optima OP-312-3. The normal force was set to $19 \mathrm{kN}$ during the simulation, which is applied by a vertical hydraulic actuator. The compression load cell Omega LPCH-5-M12 was used to control the vertical compression.

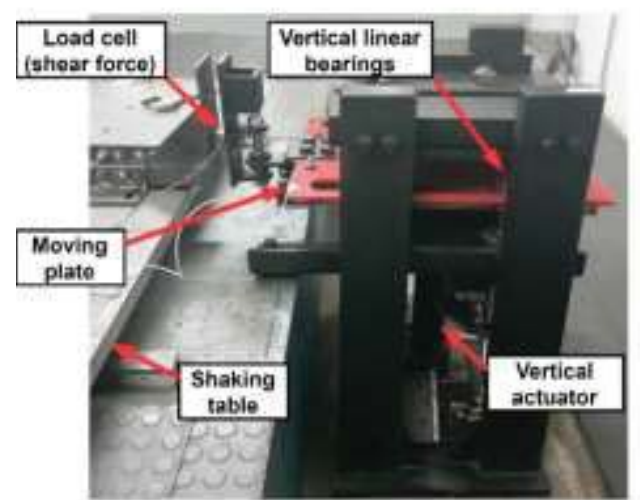

(a)

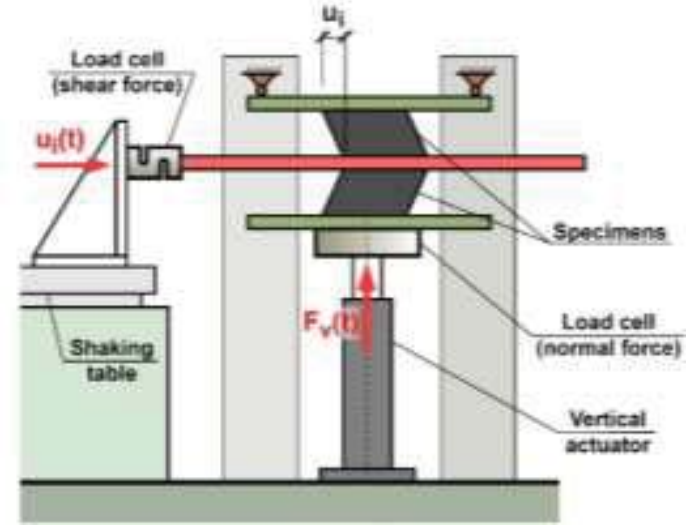

(b)

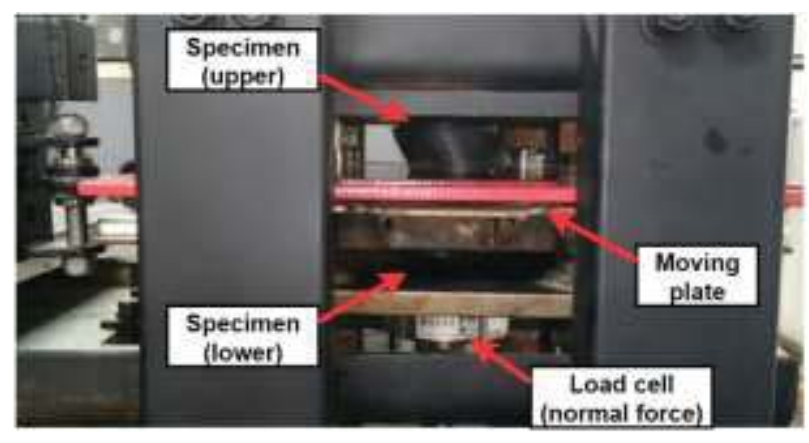

(c)

Figure 8: (a) Experimental setup, (b) Experimental setup scheme, and (c) Deformed U-FREI. 


\subsection{Transfer systems}

The RTHS control scheme is shown in Figure 9, where the horizontal control displacement is achieved through an actuator Shore Wester 911D, which has a linear variable differential transformer (LVDT). This LVDT allows to measure the displacement of the actuator piston with higher precision. This actuator is activated by a hydraulic pump that presents a maximum flow of 13.2 liters per minute. Particularly, the system pump-actuator or plant was modeled as a continuous system with one pole at the origin, without zeros, a nominal gain of 14, and a delay of 33 milliseconds. Due to the considerable noise in the LVDT measure, a Kalman filter was designed to obtain an adequate signal, according to the RTHS scope. As shown in Figure 9, the plant was feed-back using the filtered actuator displacement, $x_{m, f}[k T]$, and a unit delay. This close loop generates a stable system, in contrast to the marginal stability of the plant in open loop. Moreover, the internal loop can filter the high frequency components of the controller output, $v[k T]$. Nevertheless, the adequate tracking characteristics (amplitude and angle phase) of the horizontal transfer system were achieved using an optimal control technique in the external loop. In this case, a $H_{\infty}$ controller was employed, which Riascos et al. in [26-28] designed using the hinfstruc Matlab function, where the optimization was developed for minimizing the error signal, $e[k T]$, and the operational voltage signal, $u[k T]$.

On the other hand, the vertical control force consists of three components. The first component is a linear function expressed as $a F_{v, d}+b$, which determines the nominal voltage required by a Power Unity to apply a force, $F_{v, d}$, in the actuator. The second component is a term based on a hysteretic loop between the actuator force and the power unity voltage. This term depends on the error sign, as described in Figure 9. The third component consists of a proportional-integral (PI) controller, which fits the voltage to achieve a measured force close to the reference despite of the isolator deformation.
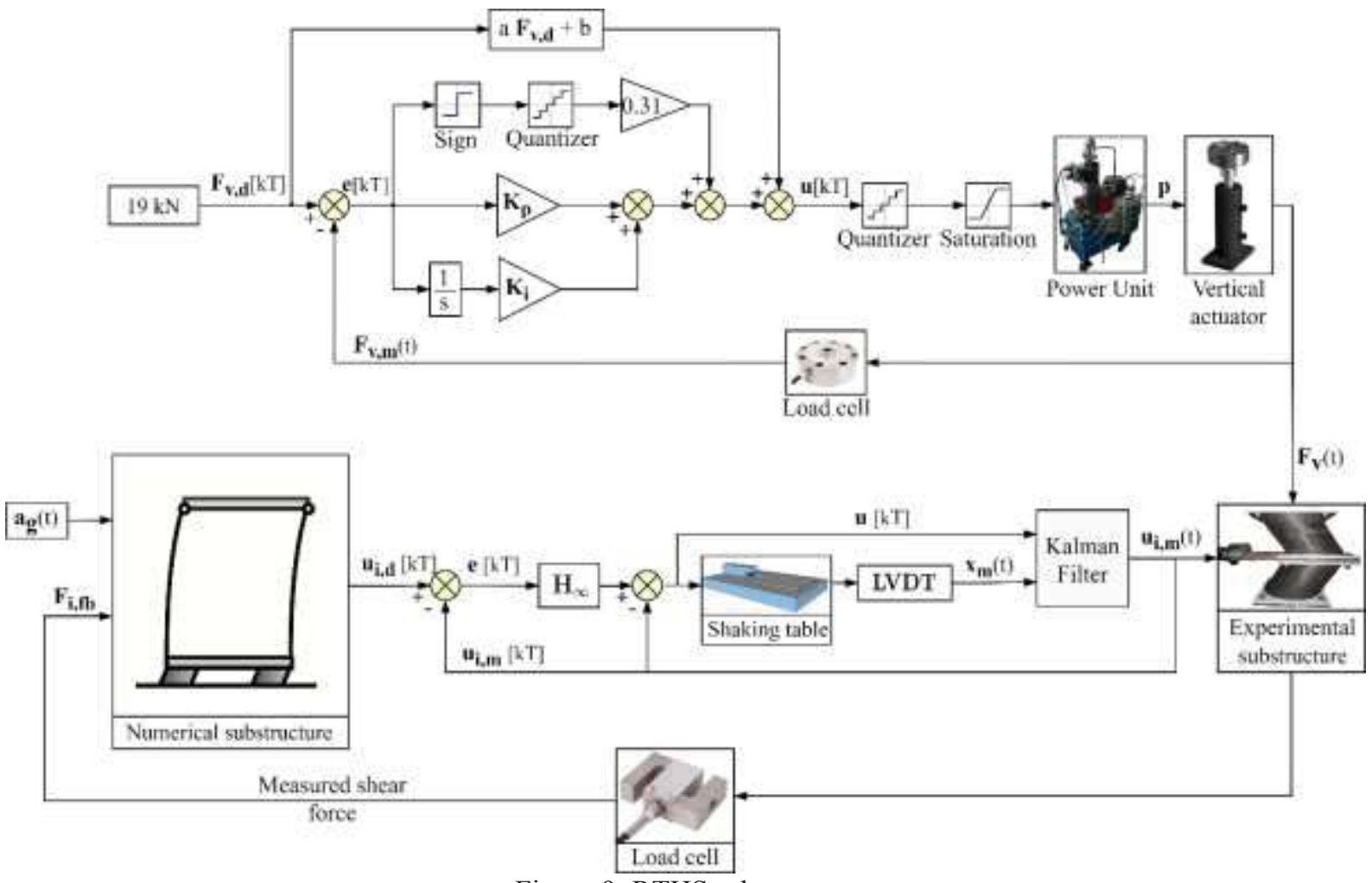

Figure 9: RTHS scheme. 


\section{RTHS IMPLEMENTATION}

This RTHS was implemented with a high-speed executing computer (SpeedGoat target machine). For this task, a host computer with Matlab's Xpc protocol and a sampling frequency of $1024 \mathrm{~Hz}$ was used. The SpeedGoat has high processing capacity to guarantee real-time evaluation of the hybrid simulation. For the CAM 50\% earthquake, a comparison between STT and RTHS approaches is presented in Figure 10.

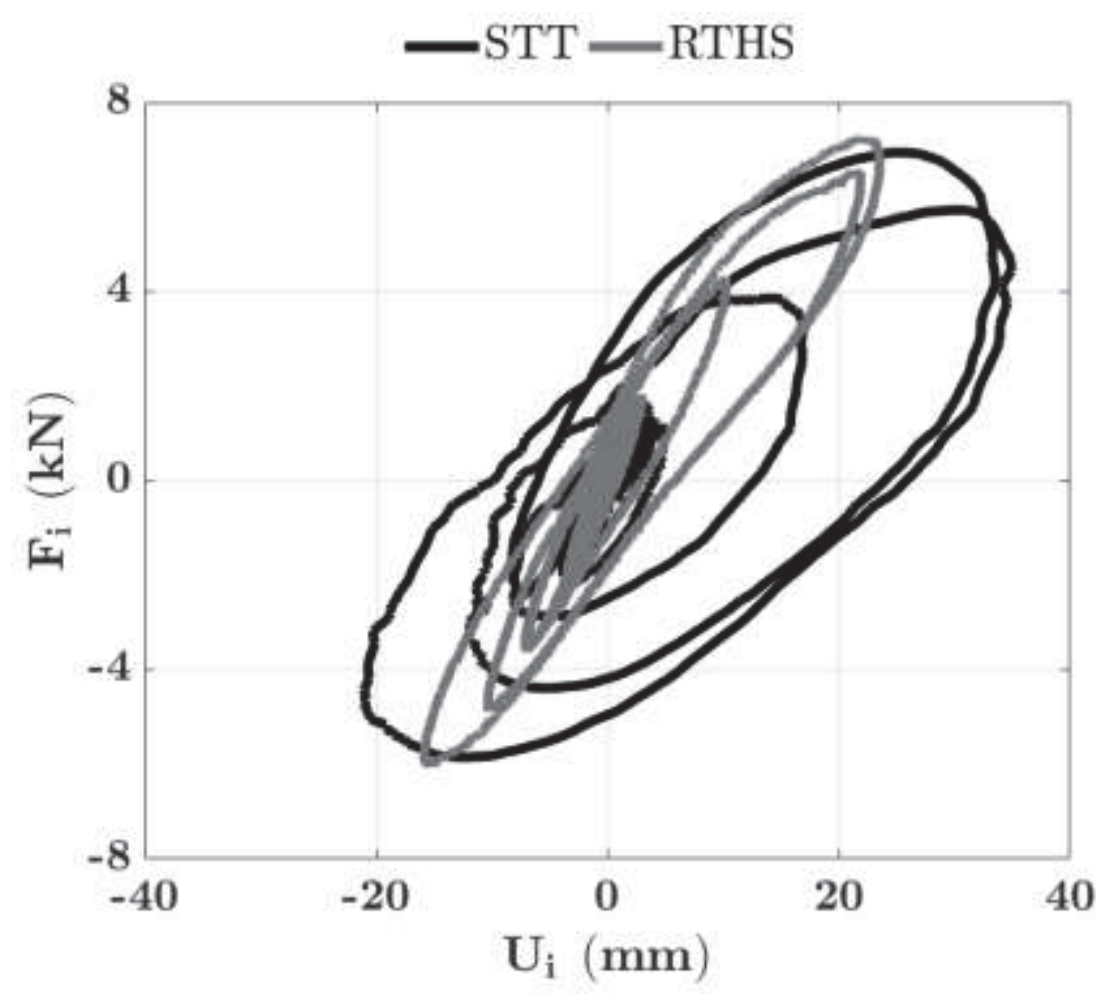

Figure 10: RTHS implementation.

\subsection{RTHS performance}

Assessment measures are adopted to determine the accuracy of the RTHS. The parameters selected in this study focused especially on the tracking accuracy of the main transfer system. These parameters involve time or frequency domains. For example, the difference of maximum error and the maximum difference errors are calculated in time domain, as given in Eqs. (4) and (5). The frequency evaluation index (FEI) compares the target and measured signals in the frequency domain using the fast Fourier transform (FFT), and the equivalent frequency $\left(f^{e q}\right)$ identifies the cycle frequency where there is the most energy of the signal, as given in Eqs. (6) and (7), respectively. The generalized amplitude, $A_{0}$, and generalized angle, $\varnothing$, depend on the FEI as expressed in Eqs. (8)-(9). Further, the delay, $\delta$, between the target and measured signals is determined in function of FEI, which is the opposite value of the FEI argument over the equivalent angular frequency, as given by Eq. (10).

$$
e_{D M}=\frac{\left.|| x_{t}\right|^{\text {max }}-\left|x_{m}\right|^{\text {max }} \mid}{\left|x_{m}\right|^{\text {max }}}
$$




$$
\begin{gathered}
e_{M D}=\frac{\left|x_{t}-x_{m}\right|^{\text {max }}}{\left|x_{m}\right|^{\text {max }}} \\
F E I=\sum_{j=1}^{N}\left\{\frac{y_{m}(j)}{y_{c}(j)} \cdot \frac{\left\|y_{c}(j)\right\|^{l}}{\sum_{i=1}^{p}\left\|y_{c}(j)\right\|^{l}}\right\} \\
f^{e q}=\frac{\sum_{j=1}^{N}\left\{\left\|y_{c}(j)\right\|^{l} \cdot f_{j}\right\}}{\sum_{j=1}^{N}\left\|y_{c}(j)\right\|^{l}} \\
A_{0}=\|F E I\| \\
\varnothing=\arctan [\operatorname{Im}(F E I) / \operatorname{Re}(F E I)] \\
\varnothing=-\frac{\emptyset}{2 \pi f^{e q}}
\end{gathered}
$$

\begin{tabular}{cccccc}
\hline$F E I$ & $f^{e q}(\mathrm{~Hz})$ & $A_{0}$ & $e_{D M}(\%)$ & $e_{M D}(\%)$ & $\delta(\mathrm{ms})$ \\
\hline $1.000-0.009 i$ & 0.52 & 1.00 & 0.27 & 2.25 & 2.87 \\
\hline \multicolumn{6}{c}{ Table 2: Assessment measures. }
\end{tabular}

\subsection{RTHS Comparison}

To validate the RTHS results some comparison indexes were proposed. These indexes allow to determine the peak and Root Mean Square (RMS) coherence between the force, acceleration, or displacement, of the RTHS $\left(y_{R T H S}\right)$, with respect to those obtained with the STT $\left(y_{S T T}\right)$. Both indexes are defined in Eqs. (11)-(12). The comparison index results are listed in Table 3, where can be observed the adequate correspondence between the force and acceleration signals obtained with the RTHS in comparison with those of the STT. However, the displacement signal between both approaches presented considerable differences. These differences indicate that the isolator displacement in the RTHS technique was approximately only $66 \%$ of the STT response. This was caused by the higher stiffness of the specimens used in this study, which also present lower damping for small deformations. In addition, the upper structure presented a maximum inter-story drift of $0.109 \%$ through the STT, whilst a drift of $0.179 \%$ was achieved with the RTHS approach. This drift difference was caused by the high stiffness of the U-FREIs employed during the RTHS, since these isolators transmit more seismic energy to the upper structure in comparison with those implemented in the STT.

$$
\begin{aligned}
& J_{\text {peak }}(\%)=100 \frac{\max \left(y_{R T H S}\right)}{\max \left(y_{S T T}\right)} \\
& J_{R M S}(\%)=100 \frac{R M S\left(y_{R T H S}\right)}{R M S\left(y_{S T T}\right)}
\end{aligned}
$$




\begin{tabular}{lcc}
\hline \multicolumn{1}{c}{ Signal } & $J_{\text {peak }}(\%)$ & $J_{R M S}(\%)$ \\
\hline Force & 104 & 105 \\
Acceleration & 91 & 95 \\
Displacement & 67 & 66 \\
\hline
\end{tabular}

Table 3: Indexes of comparison between responses for RTHS and STT.

\section{CONCLUSIONS}

The main findings of this study can be listed as follows:

- Experimental results show that the horizontal transfer system was able to generate the isolator displacement obtained from the numerical integration with good accuracy.

- The equivalent frequency of the RTHS reported an operational frequency at $0.52 \mathrm{~Hz}$, which allowed to the transfer system achieving an excellent tracking with respect to the desired displacement, where generalized amplitude of 1.00 and delay lower than 3 milliseconds were obtained.

- The RTHS achieved an adequate prediction of the peak and RMS force and acceleration of the isolated structure, despite of using a simplified model of the main structure and an experimental substructure with different mechanical characteristics in terms of stiffness and damping, with respect to that presented during the STT.

- In the RTHS technique, the isolator displacement was approximately a fraction, i.e. $66 \%$ of the STT response. This was caused by the higher stiffness that presents the specimens used in this study, which present poor damping for small deformations.

- Overall, both approaches demonstrated that the U-FREIs were able to reduce considerably the structural drift with respect to the fixed structure, and the applied RTHS methodology was verified.

- As a further development the authors will improve the numerical models of the structure in order to improve the accuracy of the RTHS.

\section{ACKNOWLEDGEMENTS}

The authors would like to acknowledge the financial support granted by the postdoctoral project with contract 80740-159-2020 (OCONT-189) (OCONT-98), from the Administrative Ministry of Science and Technology of Colombia MINCIENCIAS and the Universidad del Quindío, and the technical support provided through the project 21115 financed by MINCIENCIAS and the Universidad del Valle.

\section{REFERENCES}

[1] D. Losanno, H. A. Hadad, and G. Serino, "Design charts for eurocode-based design of elastomeric seismic isolation systems," Soil Dyn. Earthq. Eng., vol. 119, pp. 488-498, 2019.

[2] D. Losanno, H. A. Hadad, and G. Serino, "Seismic behavior of isolated bridges with additional damping under far-field and near fault ground motion," Earthquakes Struct., 
vol. 13 , no. 2 , pp. 119-130, 2017.

[3] D. Losanno, M. Spizzuoco, and G. Serino, "Optimal design of the seismic protection system for isolated bridges," Earthquakes Struct., vol. 7, no. 6, pp. 969-999, 2014.

[4] D. Losanno, M. Spizzuoco, and G. Serino, "Design and retrofit of multistory frames with elastic-deformable viscous damping braces," J. Earthq. Eng., vol. 23, no. 9, pp. 1441$1464,2019$.

[5] I. Nuzzo, D. Losanno, and N. Caterino, "Seismic design and retrofit of frame structures with hysteretic dampers: a simplified displacement-based procedure," Bull. Earthq. Eng., vol. 17, no. 5, pp. 2787-2819, 2019.

[6] I. Nuzzo, D. Losanno, F. Cilento, and N. Caterino, "Analytical and numerical modelling of shear-link device for seismic energy dissipation in frame structures," Eng. Struct., vol. 214, p. 110630, 2020.

[7] P. T. Daniel Gomez, Johannio Marulanda, "SISTEMAS DE CONTROL PARA LA PROTECCIÓN DE ESTRUCTURAS CIVILES SOMETIDAS A CARGAS DINÁMICAS," Dyna, vol. 155, pp. 77-89, 2008.

[8] J. C. De la Llera, C. Lüders, P. Leigh, and H. Sady, "Analysis, testing, and implementation of seismic isolation of buildings in Chile," Earthq. Eng. Struct. Dyn., vol. 33, no. 5, pp. 543-574, 2004.

[9] H. Toopchi-Nezhad, M. J. Tait, and R. G. Drysdale, "Shake table study on an ordinary low-rise building seismically isolated with SU-FREIs (stable unbonded-fiber reinforced elastomeric isolators)," Earthq. Eng. Struct. Dyn., vol. 38, no. 11, pp. 1335-1357, 2009.

[10] G. Mosqueda, B. Stojadinovic, and S. A. Mahin, "Real-time error monitoring for hybrid simulation. Part I: methodology and experimental verification," J. Struct. Eng., 2007.

[11] Y. Qian, G. Ou, A. Maghareh, and S. J. Dyke, "Parametric identification of a servohydraulic actuator for real-time hybrid simulation," Mech. Syst. Signal Process., 2014.

[12] F. Lin, A. Maghareh, S. J. Dyke, and X. Lu, "Experimental implementation of predictive indicators for configuring a real-time hybrid simulation," Eng. Struct., vol. 101, pp. 427438, 2015.

[13] S. Strano and M. Terzo, "Implementation and validation of a hybrid testing procedure for base-isolated structures," in Lecture Notes in Engineering and Computer Science, 2016.

[14] A. Calabrese, S. Strano, and M. Terzo, "Real-time hybrid simulations vs shaking table tests: Case study of a fibre-reinforced bearings isolated building under seismic loading," Struct. Control Heal. Monit., vol. 22, no. 3, pp. 535-556, 2015.

[15] R. Zhang, B. M. Phillips, S. Taniguchi, M. Ikenaga, and K. Ikago, "Shake table real-time hybrid simulation techniques for the performance evaluation of buildings with inter-story isolation," Struct. Control Heal. Monit., vol. 24, no. 10, pp. 1-19, 2017.

[16] D. Gomez, S. J. Dyke, and A. Maghareh, "Enabling role of hybrid simulation across NEES in advancing earthquake engineering," Smart Struct. Syst, vol. 15, no. 3, pp. 913929, 2014.

[17] D. Losanno, I. E. M. Sierra, M. Spizzuoco, J. Marulanda, and P. Thomson, "Experimental performance of unbonded polyester and carbon fiber reinforced elastomeric isolators under bidirectional seismic excitation," Eng. Struct., vol. 209, p. $110003,2020$.

[18] D. Losanno, I. E. M. Sierra, M. Spizzuoco, J. Marulanda, and P. Thomson, "Experimental assessment and analytical modeling of novel fiber-reinforced isolators in unbounded configuration," Compos. Struct., vol. 212, pp. 66-82, 2019.

[19] G. Magliulo et al., "Shake table tests on infill plasterboard partitions," Open Constr. Build. Technol. J., vol. 6, no. 1, 2012. 
[20] I. E. M. Sierra, D. Losanno, S. Strano, J. Marulanda, and P. Thomson, "Development and experimental behavior of HDR seismic isolators for low-rise residential buildings," Eng. Struct., vol. 183, pp. 894-906, 2019.

[21] N. Vaiana, S. Sessa, F. Marmo, and L. Rosati, "A class of uniaxial phenomenological models for simulating hysteretic phenomena in rate-independent mechanical systems and materials," Nonlinear Dyn., vol. 93, no. 3, pp. 1647-1669, 2018.

[22] N. Vaiana, D. Losanno, and N. Ravichandran, "A novel family of multiple springs models suitable for biaxial rate-independent hysteretic behavior," Comput. Struct., vol. 244, p. 106403, 2021.

[23] N. Vaiana, S. Sessa, and L. Rosati, "A generalized class of uniaxial rate-independent models for simulating asymmetric mechanical hysteresis phenomena," Mech. Syst. Signal Process., vol. 146, p. 106984, 2021.

[24] D. Losanno et al., "Recycled versus natural-rubber fiber-reinforced bearings for base isolation: review of the experimental findings," J. Earthq. Eng., pp. 1-20, 2020.

[25] D. Losanno, M. Spizzuoco, and A. Calabrese, "Bidirectional shaking-table tests of unbonded recycled-rubber fiber-reinforced bearings (RR-FRBs)," Struct. Control Heal. Monit., vol. 26, no. 9, p. e2386, 2019.

[26] C. Riascos, J. Marulanda Casas, and P. Thomson, "Semi-active tuned liquid column damper implementation with real-time hybrid simulations," in Active and Passive Smart Structures and Integrated Systems 2016, 2016, vol. 9799, p. 979919.

[27] C. A. Riascos-González, P. Thomson, and S. Dyke, "Performance evaluation of a nonlinear tuned mass damper through real-time hybrid simulation," INGE CUC, vol. 15, no. 2, pp. 11-22, 2019.

[28] C. Riascos, J. Marulanda, and P. Thomson, "Structural control of a grandstand using a semi-active pressurized tuned liquid column damper considering effects of passive crowds," Struct. Control Heal. Monit., 2019. 